\title{
Frequency and Outcome of Hepatic Arterial Thrombosis in Recipients of Living Donor Liver Transplantation
}

\author{
Kaleem Ullah, Abdul Wahab Dogar, Shams Uddin, Syed Hasnain, Bilal Ahmad and Abdul Ghaffar \\ Department of Liver Transplant, Pir Abdul Qadir Shah Jeelani Institute of Medical Sciences, Gambat, Sindh, Pakistan
}

\begin{abstract}
ABASTRACT
Objective: To determine the frequency, risk factors, and management of hepatic arterial thrombosis (HAT) in recipients of living donor living transplantation.

Study Design: Cohort study.

Place and Duration of Study: Department of Liver Transplant, Pir Abdul Qadir Shah Jeelani Institute of Medical Sciences, Gambat, Sindh, Pakistan, from 1st January 2019 to $31^{\text {st }}$ July 2020.

Methodology: Two hundred and forty living donor liver transplants (LDLT) recipients' data were evaluated. Frequencies of HAT were recorded, and various risk factors for the development of HAT were analysed by comparing HAT group $(n=12)$ and nonHAT group $(n=228)$. Management and outcome of HAT cases were also reviewed. Statistical analysis of this study was done with SPSS software version 21.

Results: Out of 240 patients, 212 (88.3\%) were males. Overall mean age was $39.40 \pm 12.14$ years. Mean model for end-stage liver disease (MELD) score was $18.70 \pm 4.98$. Overall male to female ratio was 7.5:1. The common indication for LDLT in these patients was chronic liver disease secondary to hepatitis B and C virus infection in $85 \%$ of patients. Postoperative HAT incidence was found as $5 \%$. Risk factor found statistically significant was intraoperative platelet transfusion.

Conclusion: HAT is a deadly complication and needs early detection to avoid graft loss. The risk factor documented in this study should be avoided, if possible. Moreover, prompt and quick action is necessary for re-vascularisation to avoid re-transplantation.
\end{abstract}

Key Words: Living donor, Hepatic arterial thrombosis, Liver transplantation.

How to cite this article: Ullah K, Dogar AW, Uddin S, Hasnain S, Ahmad B, Ghaffar A. Frequency and Outcome of Hepatic Arterial Thrombosis in Recipients of Living Donor Liver Transplantation. J Coll Physicians Surg Pak 2021; 31(08):897-902.

\section{INTRODUCTION}

Liver transplantation (LT) is the gold standard treatment for end-stage liver disease. Post LT vascular complications are quite common despite improvement and innovations in vascular anastomotic techniques. ${ }^{1}$ Hepatic artery thrombosis (HAT) is one of the most catastrophic vascular complications in post LT recipients, with an overall incidence of $2 \%$ to $9 \%$. ${ }^{2,3}$

HAT is one of the major causes for graft failure in post-LT patients in more than $50 \%$ of cases. ${ }^{4}$ Re-transplantation is needed, if HAT is not timely addressed and managed. ${ }^{5}$ The exact causes of HAT are still not known, but factors responsible for this complication can be divided into surgical technique-related factors, and donor/recipient-related factors (that affect directly or indirectly influencing other factors that predispose to thrombosis). ${ }^{6}$

Correspondence to: Dr. Kaleem Ullah, Department of Liver Transplant, Pir Abdul Qadir Shah Jeelani Institute of Medical Sciences, Gambat, Sindh, Pakistan

E-mail:drkaleempk@gmail.com

Received: March 24, 2021; Revised: June 15, 2021;

Accepted: July 13, 2021

DOI: https://doi.org/10.29271/jcpsp.2021.08.897
These risk factors include pediatric recipient, small diameter artery, prolonged arterial clamping, arterial kink, and intimal dissection. ${ }^{7}$ LDLT involves complex surgical techniques and a small-caliber donor artery (a potential risk factor for HAT) ${ }^{8} \mathrm{HAT}$ related risk factors may vary from centre to centre, that is why the exact etiology of this complication remains debatable. ${ }^{9}$

The aim of the present study was to review a single-institution experience with the spectrum and management of HAT in adult recipients ofLDLT.

\section{METHODOLOGY}

This single-centre cohort study was performed retrospectively at Department of Liver Transplant, Pir Abdul Qadir Shah Jeelani Institute of Medical Sciences, Gambat, Sindh, Pakistan. Up to 240 living donor liver transplants recipients' data were evaluated, who were operated from $1^{\text {st }}$ January 2019 to $31^{\text {st }}$ July 2020. A baseline demographic and detailed clinical data were collected from the recipients' database.

Per protocol living donors, with age range 18 to 40 years with no comorbidity, with compatible ABO blood group with the recipient, having normal preoperative laboratory parameters, favourable anatomy on liver dynamic CT scan and MRCP, were selected as donors. Donor anatomy, graft size, and the future 
liver remnant were calculated preoperatively. The transplant procedure was a standard LDLT procedure. Details of preoperative assessment of all donors and recipients were taken by cardiologist, pulmonologist, and anesthetist.

High hilar porta dissection technique was used for preserving appropriate hepatic arterial length after taking control of hepatic artery proper/common hepatic artery by applying a vascular bulldog clamp for minimising the incidence of intimal dissection. Left and right hepatic arteries were separated from the bile ductand portal vein.

Hepatic arterial reconstruction was based on the quality, caliber, and length of graft and recipient hepatic arterial anatomy. Before anastomosis, both donor and recipient arteries were checked for intimal dissection, alignment; and margins were refreshed. Care was taken to prevent arterial redundancy. Hepatic arterial reconstruction was done with interrupted technique under 3.5 magnification loupes by a consultant transplantsurgeon with at least three years ofexperience. The suture material used for anastomosis was polypropylene suture $7 / 0$ or $8 / 0$.

In the majority of cases, graft artery was anastomosed with recipient hepatic artery, i.e. right/left hepatic artery or hepatic artery proper, depending upon caliber, flow, and quality of the artery. Extra-hepatic arterial inflow was given as an alternative incases with hepatic arterial dissection.

At the end of implantation, vascular patency and flow velocities were confirmed on intraoperative Doppler ultrasound. Biliary reconstruction was done with duct-to-duct anastomosis.

As per protocol for early detection of HAT, liver Doppler ultrasonography of all recipients were performed for the first five days and then at discharge. Moreover, daily LFTs of all patients were done till discharge. After five days on need base, Doppler ultrasound were performed in cases where elevated liver enzymes were noted on routine daily LFTS.

Anticoagulant therapy was not routinely administered. Anticoagulation therapy was individualised, based upon INR and risk factors like BMI, history of diabetes/hypertension, smoking, prolong bedridden patients, those having multiple arterial anastomoses, interposition grafts, and technically demanding arterial reconstruction. Prophylactic anticoagulation was done with intravenous low molecular weight heparin (Enoxaparin sodium) with a dose of 1 to $2 \mathrm{mg} / \mathrm{kg}$ body weight. Anticoagulation usually started on $2^{\text {nd }}$ postoperated day or onward and continued till five days. While patients with a platelet count of less than 30 thousand, INR $>2$, those with difficult hemostasis (who were given platelets and FFPs infusion), and those having hemorrhagic drains were not given anticoagulation.

For study purpose, LDLT recipients in study were grouped into recipients with HAT (Group $A ; n=12$ ) and recipients without HAT (Group B; $n=228$ ). HAT was labelled on weak hepatic arterial signals or loss of flow on hepatic Doppler ultrasound. CT angiography was always performed for confirmation of HAT.
The management of every HAT case was discussed at a multidisciplinary meeting, participated by transplant surgeons, radiologists, critical care specialists, and transplant hepatologists. As per general policy, emergency surgical repair was the first choice for those who developed HAT within the first five days of transplantation, while the interventional radiological procedure was preferred for those who developed HAT after five days. Angioplasty or thrombolysis was simultaneously performed during diagnostic angiography.

Table I: Preoperative and postoperative parameters comparison between both groups.

\begin{tabular}{|c|c|c|c|}
\hline Parameter & $\begin{array}{c}\text { HAT } \\
\mathrm{N}=12(5 \%)\end{array}$ & $\begin{array}{c}\text { Non- HAT } \\
\mathrm{N}=228(95 \%)\end{array}$ & p-value \\
\hline Age & $36.25 \pm 11.63$ years & $39.56 \pm 12.17$ years & 0.358 \\
\hline Gender & $\begin{array}{l}M=9(75 \%) \\
F=3(25 \%)\end{array}$ & $\begin{array}{c}M=203(89 \%) \\
F=25(11 \%)\end{array}$ & 0.152 \\
\hline BMI & $21.61 \pm 4.825$ & $22.67 \pm 4.748$ & 0.450 \\
\hline DM & $01(8.3 \%)$ & $14(6.1 \%)$ & 0.548 \\
\hline HTN & $0(0 \%)$ & $04(1.8 \%)$ & $>0.999$ \\
\hline Cardiac disease & $0(0 \%)$ & $0(0 \%)$ & - \\
\hline Smoking & $2(16.7 \%)$ & $12(5.3 \%)$ & 0.149 \\
\hline Alcohol & $0(0 \%)$ & $06(2.6 \%)$ & $>0.999$ \\
\hline $\mathrm{HCC}$ & $01(8.3 \%)$ & $40(17.5 \%)$ & 0.697 \\
\hline TACE & $01(8.3 \%)$ & $31(13.6 \%)$ & $>0.999$ \\
\hline MELD-Na & $18.7 \pm 3.9$ & $18.7 \pm 5.0$ & 0.980 \\
\hline \multicolumn{3}{|l|}{ Graft type } & \multirow{5}{*}{0.184} \\
\hline Right lobe without MHV & $11(91.7 \%)$ & $156(68.4 \%)$ & \\
\hline Right lobe with MHV & $0(0 \%)$ & $27(11.8 \%)$ & \\
\hline Right lobe with partial MHV & $01(8.3 \%)$ & $39(17.1 \%)$ & \\
\hline Left lobe graft & $0(0 \%)$ & $06(2.6 \%)$ & \\
\hline Graft weight & $644.92 \pm 81.901 \mathrm{gm}$ & $686.35 \pm 136.19 \mathrm{gm}$ & 0.298 \\
\hline Warm ischemia & $27.50 \pm 7.23 \mathrm{~min}$ & $31.18 \pm 8.45 \mathrm{~min}$ & 0.140 \\
\hline Cold ischemia & $6.92 \pm 3.605 \mathrm{~min}$ & $9.10 \pm 4.461 \mathrm{~min}$ & 0.065 \\
\hline Operative duration & $512.5 \pm 69.95 \mathrm{~min}$ & $528.35 \pm 69.5 \mathrm{~min}$ & 0.442 \\
\hline \multicolumn{3}{|l|}{ Arterial inflow } & \multirow{3}{*}{0.305} \\
\hline Hepatic & $11(91.7 \%)$ & $222(97.4 \%)$ & \\
\hline Extra-Hepatic & $01(8.3 \%)$ & $06(2.6 \%)$ & \\
\hline Conduit used & $01(8.3 \%)$ & $02(0.9 \%)$ & 0.143 \\
\hline Multiple anastomosis & $01(8.3 \%)$ & $02(0.9 \%)$ & 0.143 \\
\hline Intra-op FFP transfusion & $2(16.7 \%)$ & $08(3.5 \%)$ & 0.083 \\
\hline PRBC transfusion & $7(58.3 \%)$ & $92(40.4 \%)$ & 0.241 \\
\hline Intra-op platelets transfusion & $3(25 \%)$ & $4(1.8 \%)$ & 0.003 \\
\hline Anticoagulation used & $\begin{array}{l}\text { Yes: } 02(16.67 \%) \\
\text { No: } 10(83.34 \%)\end{array}$ & $\begin{array}{l}\text { Yes: } 70(30.70 \%) \\
\text { No: } 158(69.30 \%)\end{array}$ & 0.518 \\
\hline
\end{tabular}

Patient demographics, indications for transplant, comorbid conditions, graft type, graft weight, cold and warm ischemia time, operative time, transfusion (red blood cells, fresh frozen plasma, and platelets), type of arterial anastomosis, conduit used, and anticoagulation status were compared between HAT and Non-HAT groups (Table I), Statistical analysis of this study was done with SPSS version 21.

The management and outcome of HAT and the need for re-transplantation after HAT were also reviewed (Table II).

Univariate analysis by the Chi-square or Fisher's Exact tests was done to assess the association between graft and surgical technique-related predisposing factors, i.e. recipientage, operation period, graft type, weight and the HAT incidence. 
Table II: Management summary of cases with HAT.

\begin{tabular}{|c|c|c|c|c|c|c|c|c|c|c|c|c|c|c|}
\hline $\begin{array}{l}\text { Case } \\
\text { No }\end{array}$ & $\begin{array}{c}\text { Day of } \\
\text { incidence }\end{array}$ & $\begin{array}{c}\text { Hemodynamic } \\
\text { stability }\end{array}$ & $\begin{array}{c}\text { Ionotropic } \\
\text { support }\end{array}$ & $\begin{array}{c}\text { ALT }(U / L) \\
\text { value at } \\
\text { diagnosis }\end{array}$ & $\begin{array}{l}\text { ALT (U/L) } \\
\text { value } \\
\text { after } \\
\text { treatment } \\
\text { on next } \\
\text { day }\end{array}$ & $\begin{array}{c}\text { AST }(U / L) \\
\text { value at } \\
\text { diagnosis }\end{array}$ & $\begin{array}{c}\text { AST }(U / L) \\
\text { value } \\
\text { after } \\
\text { treatment } \\
\text { on next } \\
\text { day }\end{array}$ & $\begin{array}{c}\text { Lactate } \\
\text { level at } \\
\text { diagnosis } \\
\text { (mmol/L) }\end{array}$ & \begin{tabular}{|c|} 
Lactate \\
level \\
after \\
treatment \\
on next \\
day \\
(mmol/L) \\
\end{tabular} & INR & $\begin{array}{c}\text { Platelet } \\
\text { count } \\
\text { (cells } / \mathbf{m m} 3 \text { ) }\end{array}$ & $\begin{array}{c}\text { Interval } \\
\text { to } \\
\text { procedure }\end{array}$ & $\begin{array}{l}\text { Procedure } \\
\text { performed }\end{array}$ & $\begin{array}{c}\text { Successful } \\
\text { outcome }\end{array}$ \\
\hline 1 & $3^{\text {rd }}$ & yes & Nil & 473 & 257 & 301 & 224 & 4.7 & 2.2 & 1.8 & 90,000 & 4 hours & Surgical exploration & yes \\
\hline 2 & $5^{\text {th }}$ & yes & Nil & 403 & 221 & 298 & 213 & 2.7 & 2.1 & 1.4 & 76,000 & 3 hours & Surgical exploration & Yes \\
\hline 3 & $2^{\text {rd }}$ & yes & yes & 551 & 324 & 342 & 287 & 2.6 & 1.8 & 1.6 & 84,000 & 4 hours & Surgical exploration & No \\
\hline 4 & $8^{\text {th }}$ & yes & Nil & 331 & 187 & 221 & 175 & 5.0 & 2.2 & 1.8 & 70,000 & 4 hours & $\begin{array}{l}\text { Interventional } \\
\text { Radiology }\end{array}$ & Yes \\
\hline 5 & $4^{\text {th }}$ & yes & Nil & 654 & 458 & 307 & 252 & 3.3 & 1.7 & 1.7 & 51,000 & 4 hours & Surgical exploration & Yes \\
\hline 6 & $4^{\text {th }}$ & yes & Nil & 199 & 105 & 101 & 80 & 2.8 & 1.9 & 1.9 & 62,000 & 3.5 hours & Surgical exploration & Yes \\
\hline 7 & $6^{\text {th }}$ & yes & Nil & 321 & 202 & 197 & 132 & 2.1 & 1.7 & 1.5 & 48,000 & 4. hours & $\begin{array}{c}\text { Interventional } \\
\text { Radiology }\end{array}$ & Yes \\
\hline 8 & $4^{\text {th }}$ & yes & Nil & 256 & 145 & 123 & 99 & 2.5 & 1.6 & 1.7 & 165,000 & 4 hours & Surgical exploration & Yes \\
\hline 9 & $4^{\text {th }}$ & yes & Nil & 456 & 310 & 335 & 275 & 2.2 & 1.6 & 1.8 & 83,000 & 3.5 hours & Surgical exploration & Yes \\
\hline 10 & $7^{\text {th }}$ & yes & Nil & 387 & 280 & 280 & 221 & 4.8 & 1.8 & 1.2 & 60,000 & 3.5 hours & $\begin{array}{c}\text { Interventional } \\
\text { Radiology }\end{array}$ & Yes \\
\hline 11 & $1^{\text {st }}$ & yes & yes & 432 & 316 & 346 & 268 & 1.8 & 1.5 & 1.4 & 83,000 & 4 hours & Surgical exploration & Yes \\
\hline 12 & $4^{\text {th }}$ & yes & Nil & 476 & 335 & 367 & 297 & 1.7 & 1.4 & 1.5 & 105,000 & 3 hours & Surgical exploration & Yes \\
\hline
\end{tabular}

A $p$-value of $<0.05$ was considered statistically significant. For quantitative data, mean \pm SD was given and evaluated by an independent sample t-test. For categorical variables, frequencies and percentages were given and evaluated by Chi-square or Fisher's Exact test.

Overall survival was calculated by applying Kaplan-Meier survival analysis. The study was conducted after approval by the Hospital Ethical Committee.

\section{RESULTS}

Overall mean age was $39.40 \pm 12.14$ years. The mean MELD score was $18.70 \pm 4.98$. Out of 240 cases, 212 (88.3\%) were males and 28 (11.7\%) were females. The male-to-female ratio was $7.5: 1$.

The common indication for LDLT in these patients was chronic liver disease secondary to hepatitis $B$ and $C$ virus infection in 204 (85\%) patients, while cryptogenic cirrhosis found in $13(5.4 \%)$, primary biliary cirrhosis and primary sclerosing cholangitis in $1(0.4 \%)$ case each, NASH in $2(0.8 \%)$, autoimmune hepatitis in $3(1.3 \%)$, Wilson disease in 6 (2.5\%), Budd Chiari syndrome in $8(3.3 \%)$ and progressive familial intrahepatic cholestatic diseases in $2(0.8 \%)$ cases.

Postoperative HAT occurred in 12 (5\%) recipients. Hepatocellular carcinoma (HCC) was found in $8.3 \%$ in the HAT group, while $17.5 \%$ in the non-HAT group. TACE history was positive in $8.3 \%$ cases in the HAT group, while in $13.6 \%$ of cases in the non-HAT group. No significant difference was found by comparing variables like, gender, MELD score, BMI, comorbid, HCC, and TACE in the two groups (Table I).

Moreover, no significant difference was found by comparing operative variables like mean cold and warm ischemia time, duration of surgery, graft weight, conduit use, multiple anastomoses, PRBCs, and FFPs transfusion in both groups (Table I).
The only significant comparable operative variable found was platelets transfusion. Platelets transfusion was found in $3(25 \%)$ cases in the HAT group, while in $4(1.75 \%)$ cases with a significant $p$-value of 0.003 .

Postoperatively 72 (30\%) high risk patients out of 240 patients were anticoagulated and $168(70 \%)$ were not given anticoagulation. The incidence of HAT was $2.78 \%$ in the high risk group versus $5.95 \%$ in low risk group. Seventy (30.70\%) anticoagulated cases were in the non-HAT group and 2 (16.67\%) of anticoagulated cases were in the HAT group. The comparison in both groups was not significant with a $p$ value of 0.518 .

The median day for HAT presentation was 4. All HAT patients were hemodynamically stable, while $2(16.67 \%)$ cases were maintaining hemodynamics with inotropic support. Elevated liver enzymes (ALT, AST) were found in all (100\%) HAT cases, while rising lactate was noted only in $3(25 \%)$ cases. Nine (75\%) cases were diagnosed on daily routine Doppler ultrasound done during the $1^{\text {st }}$ five postoperative days, while 3 (25\%) cases were diagnosed on Doppler ultrasound done for liver enzymes elevation after $5^{\text {th }}$ postoperative day $1^{\text {st }}$. All cases were successfully managed within four hours of diagnosis. Out of the 12 HAT cases, 9 (75\%) were surgically explored and $3(25 \%)$ cases were managed by vascular intervention techniques. Five $(41.7 \%)$ cases were managed by surgical thrombectomy and re-anastomosis. Donor arterial dissection was found in $2(16.7 \%)$ cases and was managed with revision of anastomosis. One patient developed Re-HAT and was offered re-transplantation, but not performed due to donor unavailability. While in $2(16.7 \%)$ cases, recipient arterial dissections were found, which were managed by giving inflow with saphenous venous graft conduit from suprarenal aorta, due to inappropriate artery length.

In three HAT cases, managed by an interventional radiologist, angioplasty was done in two cases; while in $3^{\text {rd }}$ case, stenting could not be done and the patient was treated with intravascular thrombolytic therapy. All these cases survived (Table II). 
Comparison of survival between both groups showed a better survival rate ( $88.6 \%$ versus $83.3 \%$ ) in the non-HAT group compared to non-HAT group.

\section{DISCUSSION}

The incidence of HAT in this study was $5 \%$, which is comparable with the literature. ${ }^{10,11}$ Bekker et al. published a systematic review about incidence, risk factors, and outcome of early HAT in liver transplant recipients. They reported an incidence of $4.4 \% .{ }^{10}$ While, Salvalaggio et al. reported an incidence of $3.5 \%$ of HAT in adult LDLT versus $0.8 \%$ incidence in DDLT. The reasons for the higher incidence in LDLT was quoted as the surgical complexity (short length and small diameter donor arteries liver grafts in LDLT). ${ }^{11}$

In the literature, risk factors for HAT development listed are prolonged cold ischemia, PRBCs, FFPs, and platelets transfusion. ${ }^{12,13}$ This study demonstrated platelet transfusion as a risk factor for HAT development. Platelet transfusion is usually indicated in difficult operative hemostasis. But on the other hand, platelets are well known for playing a pivotal role in arterial thrombosis development. It is both foe-andfriend in liver transplantation. ${ }^{14}$

Regarding surgical technique, literature has shown that complex arterial reconstruction and reconstruction with multiple anastomoses are risk factors for HAT. ${ }^{15-18}$ Conduit usage and small lumen artery were declared risk factors in another study. ${ }^{10}$ In this study, the percentage number of cases with conduit use and multiple anastomoses were more in the HAT group in comparison to the non-HAT group; but this comparison was not statistically significant, the reason may be that anticoagulations in these higher-risk cases were done.

Nishida et al. stressed the diagnosing of early HAT, based on regular Doppler ultrasound examination of the graft. They reported a major decrease in graft ischemia with timely diagnosis and urgent revascularisation. ${ }^{19}$ With the mentioned protocol for graft surveillance for early HAT detection, there was not a single ischemic graft in all HAT cases. Angiographic confirmation of HAT is needed when Doppler ultrasound findings are equivocal. ${ }^{12,19}$ This study also follows the same protocol for confirmation of HAT with CT angiography.

Traditionally for HAT management, re-transplantation was the procedure of choice. However; a limited donor pool restricted this approach. So, alternatively, urgent revascularisation became the first choice; and studies have shown excellent results with urgent revascularisation in timely diagnosed cases. ${ }^{10,12}$ However, Vrochides et al. suggested that re-transplantation is necessary for HAT, as surgical thrombectomy and anastomotic revision did not show any improvement in graft survival. ${ }^{20}$ But findings of few other studies were contradictory to their study, as these studies showed excellent results with revascularisation. ${ }^{21,22}$ This study also showed excellent results with revascularisation; and hence, the authors prefer revascularisation as a procedure of the choice for the management of HAT and re-transplantation for those with ischemic grafts.

Treatment modality for HAT depends on the time of presentation. ${ }^{23}$ The authors prefer surgical exploration for cases presented within the first five days post-transplantation, while intervention radiological procedure for cases presented late after five days. The outcome success of the authors with this approach was tremendous. As ideal treatment for HAT, (surgical or non-surgical therapies including IR) remains controversial. ${ }^{24}$ Kogut et al. published his experience of 26 HAT patients, where revascularisation was done in $46 \%$ cases with intra-arterial thrombolysis. However, subsequent surgical intervention was needed in nearly half $(42 \%)$ of these cases. ${ }^{25}$ The authors managed our three cases successfully with interventional radiological techniques, two with angioplasty, and one with intravascular thrombolysis.

Bekker et al. published overall mortality of $33.3 \%$ with HAT patients, with a range of $0 \%-80 \% .{ }^{10}$; while in this study, mortality of $16.7 \%$ was recorded in HAT cases.

In this study, re-transplantation was needed for a single case in which donor artery arterial dissection was found. The need for re-transplantation in this study was significantly lower, the reason of which was early detection of HAT followed by quick re-vascularisation. The authors managed all the cases within four hours of HAT detection; though a study has reported a retransplantation rate of $50 \%-75 \%$ after HAT. ${ }^{12}$

The limitation of this single-centre study was relatively smaller sample-sized groups. The association of HAT with platelet transfusion may not be significant, if studied with larger sample size. So, the authors recommend further studies with a larger population to determine its exact association with HAT incidence.

\section{CONCLUSION}

HAT is a deadly complication and needs early detection to avoid graft loss. The protocol mentioned in this study for early detection of HAT showed satisfactory results, as no ischemic graft was recorded. The risk factor documented in this study was intraoperative platelet transfusion which should be avoided, if possible. Moreover, prompt and quick action is necessary for re-vascularisation to avoid re-transplantation.

\section{ETHICAL APPROVAL:}

The Ethics Committee of the Hospital provided approval for this study.

\section{PATIENTS' CONSENT:}

Since it is a retrospective study, so patients' consent is not required. 


\section{CONFLICT OF INTEREST:}

The authors declared no conflict of interest.

\section{AUTHORS' CONTRIBUTION:}

KU: Study conception and design.

AWD: Critical revision.

SU: Analysis and interpretation of data.

$\mathrm{SH}$ : Drafting of manuscript.

BA: Review of discussion.

AG: Acquisition of data.

\section{REFERENCES}

1. Steinbrück K, Enne M, Fernandes R, Martinho JM, Balbi E, Agoglia L, et al. Vascular complications after living donor liver transplantation: A Brazilian, single-center experience. Intransplantation Proc 2011; 43(1):pp.196-8. doi: 10.1016/j.transproceed.2010.12.007.

2. Proposito D, Garcìa G, Jimènez C, Pinto G, De La Cruz J. Assessment of risk factors in the incidence of hepatic artery thrombosis in a consecutive series of 687 liver transplantations. Annaliitaliani Di Chirurgia 2001; 72(2):187-205.

3. Abou Ella KA, Al Sebayel MI, Ramirez CB, Rabea HM. Hepatic artery thrombosis after orthotopic liver transplantation. Saudi Med J 2001; 22(3):211-4.

4. Pareja E, Cortes M, Navarro R, Sanjuan F, López R, Mir J. Vascular complications after orthotopic liver transplantation: Hepatic artery thrombosis. Transplant Proc 2010; 42(8):2970-2. doi: 10.1016/j.transproceed.2010.07.063.

5. Wozney P, Zajko AB, Bron KM, Point S, Starzl TE. Vascular complications after liver transplantation: A 5-year experience. AJR Am J Roentgenol 1986; 147:657-63. doi: 10.2214/ajr.147.4.657.

6. Abou El-Ella K, Al Sebayel M, Ramirez C. Outcome and risk factors of hepatic artery thrombosis after orthotopic liver transplantation in adults. Transplant Proc 2001; 33(5):2712-3. doi: 10.1016/s0041-1345(01)02157-1.

7. Miyagi S, Kawagishi N, Nakanishi W, Fujio A, Miyazawa K, Maida K. Risk factors for hepatic artery thrombosis after microsurgical vascular reconstruction in liver transplantation. Transplant Proc 2013; 45(5):1994-6. doi: 10.1016/j.transproceed.2012.12.030.

8. Silva MA, Jambulingam PS, Gunson BK, Mayer D, Buckels JAC, Mirza DF, et al. Hepatic artery thrombosis following orthotopic liver transplantation: A 10-year experience from a single centre in the United Kingdom. Liver Transpl 2006; 12(1):146. doi: 10.1002/lt.20566.

9. Oh C, Pelletier S, Sawyer R, Dacus AR, McCullough CS, Pruett $T L$, et al. Uni- and multi-variate analysis of risk factors for early and late hepatic artery thrombosis after liver transplantation. Transplantation 2001; 71(6):767-72. doi: 10.1097/00007890-200103270-00014.

10. Bekker J, Ploem S, DE Jong KP. Early hepatic artery thrombosis after liver transplantation: A systematic review of the incidence, outcome and risk factors. Am J Transplant 2009; 9(4):746-57. doi: 10.1111/j.1600-6143.2008.02541.x.

11. Salvalaggio PR, Modanlou KA, Edwards EB, Harper AM, Abecassis MM. Hepatic artery thrombosis after adult living donor liver transplantation: The effect of center volume.
Transplantation 2007: 84(7):926. doi: 10.1097/01.tp.0000281554.00247.92.

12. Pinna $A D$, Smith CV, Furukawa $H$, Starzl TE, Fung JJ. Urgent revascularisation of liver allografts after early hepatic artery thrombosis. Transplantation 1996; 62(11):1584-7. doi: 10.1097/00007890-199612150-00010.

13. Hatano E, Terajima H, Yabe S, Asonuma K, Egawa H, Kiuchi $\mathrm{T}$, et al. Hepatic artery thrombosis in living related liver transplantation. Transplantation 1997; 64(10):1443-6. 12. doi: 10.1097/00007890-199711270-00012.

14. Pereboom IT, Lisman T, Porte RJ. Platelets in liver transplantation: friend or foe? Liver Transplantation 2008; 14(7):923-31. doi: 10.1002/lt.21510.

15. Piscaglia F, Vivarelli M, La Barba G, Morselli-Labate AM, Taddei S, Cucchetti A, et al. Analysis of risk factors for early hepatic artery thrombosis after liver transplantation. Possible contribution of reperfusion in the early morning. Dig Liver Dis 2007; 39(1):52-59. doi: 10.1016/j.dld.2006. 08.004.

16. Soliman $T$, Bodingbauer $M$, Langer $F$, BerlakovichGA, Wamser P, Rockenschaub S, et al. The role of complex hepatic artery reconstruction in orthotopic liver transplantation. Liver Transpl 2003; 9(9):970-5. doi: 10.1053/jlts.2003.50167.

17. Sugi MD, Albadawi $H$, Knuttinen G, Naidu SG, Mathur AK, Moss AA, et al. Transplant artery thrombosis and outcomes. Cardiovascular Diagnosis Ther 2017; 7(Suppl 3):S219. doi: 10.21037/cdt.2017.10.13.

18. Yang Y, Zhao JC, Yan LN, Ma YK, Huang B, Yuan D, et al. Risk factors associated with early and late HAT after adult liver transplantation. World J Gastroenterol 2014; 20(30):10545. doi: 10.3748/wjg.v20.i30.10545.

19. Nishida S, Kato T, Levi D, Naveen M, Thierry B, Vianna R, et al. Effect of protocol doppler ultrasonography and urgent revascularisation on early hepatic artery thrombosis after pediatric liver transplantation. Arch Surg 2002; 137(11):1279-83. doi: 10.1001/archsurg.137.11.1279.

20. Vrochides D, Hassanain M, Metrakos P, Barkun J, Paraskevas $S$, Chaudhury $P$, et al. Re-vascularisation may not increase graft survival after hepatic artery thrombosis in liver transplant recipients. Hippokratia 2010; 14(2):115-8.

21. Singhal A, Stokes K, Sebastian A, Wright HI, Kohli V. Endovascular treatment of hepatic artery thrombosis followingliver transplantation. Transpl Int 2010; 23(3):245-56. doi: 10.1111/j.1432-2277.2009.01037.x.

22. Yamakado K, Nakatsuka A, Takaki H, Usui M, Sakurai H, Isaji $\mathrm{S}$, et al. Stent-graftfor the management of hepatic artery rupturesubsequenttotranscatheter thrombolysis and angioplasty in a livertransplant recipient. Cardiovasc Intervent Radiol 2008; 31(Suppl 2):S104. doi: 10.1007/s00270007-9188-1.

23. Vorwerk D, Gunther RW, Klever P, Riesener KP, Schumpelick $\mathrm{V}$. Angioplasty and stent placement for treatment of hepatic artery thrombosis following liver transplantation. J Vasc Interv Radiol 1994; 5(2):309-14. doi: 10.1016/s10510443(94)71489-5.

24. Song S, Kwon CH, Moon HH, Lee S, Kim JM, Joh JW, et al. Single-center experience of consecutive 522 cases of hepatic artery anastomosis in living-donor liver transplanta- 
tion. In Transplant Proc 2015; 47(6): 1905-11. doi: 10.1016/j.transproceed.2015.06.014.

25. Kogut MJ, Shin DS, Padia SA, Johnson GE, Hippe DS, Valji K.
Intra-arterial thrombolysis for hepatic artery thrombosis following liver transplantation. J Vasc Interv Radiol 2015; 26(9):1317-22. doi: 10.1016/j.jvir.2015.06.008. 